\title{
Parenting - A neglected aspect of childcare
}

\section{H Karunatilaka ${ }^{1}$}

Sri Lanka Journal of Child Health, 2002; 31: 77-81

(Key words: parenting)

While looking around for an appropriate topic for my address today, I perused through topics that my predecessors had dealt with in recent years. I noticed that we had clearly drifted away from this concept of the "disease palace" towards more community and family oriented issues in childcare. I also realised that the WHO has declared the year 2001 as the year of mental health. According to the WHO definition health is "a state of complete physical, mental and social well-being and not merely the absence of disease or infirmity". Taking this definition into consideration, I felt that, although we have embarked on diverse topics related to childcare in the past, child mental health has never been a topic of serious discussion among paediatricians. Therefore I thought it is opportune, at this juncture, to draw your attention to a somewhat neglected aspect of childcare viz. parenting, which is also appropriate to the theme chosen for the coming year, i.e. "Moulding the future citizen - a child centred approach".

Parenting, as we all know, facilitates proper mental development of the child and the care the child receives in this exercise is a cornerstone for development of his/her emotional well-being and interpersonal relationships. The caring experience that children receive not only affects their relationships with others but also influence their behaviour with their own children when they become parents. There is now overwhelming evidence that certain parenting styles are positively harmful and are particularly associated with antisocial and delinquent behaviour such as being persistently hostile, antiauthoritative, coming into conflict with law enforcement, lack of regard for social norms and lack of feeling for others, all of which are quite rampant in our society today.

The first 18 years in a child's life is the period during which profound changes occur in physical, cognitive, and social development.

${ }^{1}$ Consultant Paediatrician, Lady Ridgeway Hospital, Colombo.

* Address given on Induction as President SLCP, November 2001.
Therefore paediatricians, along with other caregivers, have a primary duty to see that this process take place optimally and to the best advantage of the child at all times. It is our responsibility as paediatricians to take stock of the current situation and step in to fill this void, even at this late stage, especially when there is a dearth of those who are primarily responsible for promoting child mental health programmes, including correct parenting.

I feel we, as practicing paediatricians, often come across wrong parenting attitudes that could be detrimental not only to the child's psyche and personality but also to the society at large. We also witness parenting errors that reinforce physical illness or encourage the child to adopt a sick role. I do not propose that we should conduct classes on parenting but we could certainly take an initiative to correct certain unhealthy parenting attitudes that we encounter in our work as professionals.

Although our ancestors may not have received any advice regarding parenting, and their parenting skills were never subjected to evaluation, the social order of yester year was not disrupted as it is today. Today society has changed and the social order is different. Today we live in a more complex society and the social milieu and expectations are different. The extended families are no more except perhaps in the rural areas of the country. The grand parents of today do not get an adequate opportunity to play a major role, unlike in the past, in infusing social values to their grand children. Mothers now leave their young children in the custody of incompetent and questionable caregivers to go for overseas employment. Corporal punishment is no longer an accepted method of disciplining children and we now know that such punishment does have an adverse psychological impact on some children. All these are new changes that have emerged and therefore there is now cause for concern about correct child rearing practices and a need has arisen to take a fresh look at this whole issue. 


\section{What is parenting?}

It is the role played by the parents to facilitate the child's healthy psychological development and personality by providing necessary care, comfort and adequate stimulation within a safe environment in line with accepted social norms. While parents must respond to the child's early helplessness and dependency, they must also encourage the child to differentiate and acquire a separate identity. To do this a balance needs to be struck between the child's need for socialization and exploratory learning versus protection and limit setting. However it is important to remember at the very outset, that in addition to parenting, several other factors also play important roles in the child's psychological development and biological maturity. Single gene defects, chromosomal abnormalities, drugs and toxins, pregnancy related complications, perinatal complications, disease (both intrauterine and in early childhood) are some of them. Other adverse environmental factors, such as poor nutrition in the mother and baby, also play an important role in the child's psychosocial development and biological maturity. Some of the adverse aetiological factors mentioned above are largely preventable and we as paediatricians have a major role to play here too.

\section{What is the setting for parenting?}

It is important to realize that the human infant is gregarious or a social animal and therefore the development of the individual child is primarily a social process. Initially, the family is the pivotal point around which this development occurs. It is the healthy relationship within families and proper parenting of children that facilitate normal childhood development without any psychological disturbance. In late childhood, however, in addition to family members, the school, peer relations and society also have some influence on their psychosocial and personality development.

\section{The main components of parenting are:}

- Provision of care

- Safety and protection

- Exercising control

- Intellectual stimulation

\section{Provision of care}

Care is basically of two types:

\section{Physical or material care}

2. Emotional care

Physical care involves the provision of food, clothing and shelter, proper medical care during illness, proper hygiene and cleanliness, education and physical comfort.

\section{Emotional care}

This is best discussed under the following four areas.

\section{Proper bonding, attachment and affection}

This is a two way process. The feeling and behaviour of parents affect the child and behaviour of the child affects the parent in a circular manner and the feed back between them modifies each person's participation in the relationship. Initially the child uses the mother as a secure base for exploring the world and any breakdown in this secure attachment will result in the child not trusting the world and finally having problems with interpersonal relationships in later life.

\section{Love and warmth}

These are self-explanatory but it is important to remember that excessive affection or excessive hatred are both ultimately damaging.

\section{Empathy}

In empathizing the parent will demonstrate concern and interest in their kids' general well being and particular experiences. This also allows parents to place themselves in their children's place appreciating experiences from their perspective.

\section{Proper parent-child interaction}

Proper communication is an integral component of parent-child interaction. Parents should not only give clear messages to the child but there must be a consistency between verbal and non-verbal communications. The father and mother should not give different and conflicting messages so that the child is totally confused in the end as to what is expected of him. Parents should also facilitate socialization by encouraging interaction with others and allowing the child to develop autonomy and self esteem. Needless to say, parents should encourage, appreciate and support the child wherever necessary. 


\section{Safety and protection}

This involves protection against exposure to dangerous people, exposure to dangerous environment such as poisons (including insect and other poisonous bites) and accidents (including home accidents). This also involves protection against allowing the child to be responsible for his own safety and not leaving young children unattended or under the care of an older child who is incapable of providing safety.

\section{Exercising control}

This involves setting of limits, application of clear rules, providing supervision to ensure that children conform to rules and positive and negative reinforcement. Positive reinforcement is appreciating or praising the child when something good is done. Reward is a form of positive reinforcement that encourages the child to repeat the same desirable behaviour. Negative reinforcement involves ignoring the child when something undesirable is done. Children do things to attract attention and if his actions are ignored he will not repeat them. However, physical punishment may take the form of positive reinforcement as the child gets the necessary attention he needs and is therefore counterproductive. Prohibition of unsupervised access to electronic media is yet another important aspect of exercising control.

\section{Intellectual stimulation}

This involves provision of age appropriate stimulation such as giving correct educational material and toys appropriate for the age and playing with the child. Provision of an opportunity to learn through exploring new situations such as visiting museums, zoological gardens and aquariums with the child and going out on holiday etc. are important. Even spending a little time in your own garden with the child studying various flora and fauna is a form of exploratory learning. Encouraging learning through formal and informal education such as relating to the child, watching television with him, playing scrabble or chess with the child are all useful aspects of intellectual stimulation.

However, provision of care, safety, proper control, and stimulation by the parents alone are not good enough for proper parenting; they must also have correct attitudes for the task of parenting.

\section{Correct attitudes for the task of parenting}

Each child must be viewed as a separate person. Parents should recognize that each child is a separate person with feelings, ideas and identity different from those of the parents. The child's needs and experiences must be recognized and addressed and over intrusiveness avoided. This is something that we often encounter. The child must be allowed to develop psychological autonomy over the years and separate himself from parents to a chosen life. Child's emotional needs must be given primacy over the parent's desires. Parents should learn to deal with their anger and frustration when dealing with young children and they must find alternate ways to ventilate their anger and frustration. Child abuse is often the outcome of anger and frustration directed at the child. Parents must take care not to repeat any of their adverse experiences for this can repeat as a chain reaction in the child. If a parent uses aggression, such as corporal punishment, or becomes abusive, the child also might resort to the same tactics when he becomes a parent. Parents must understand correct limit setting and realistic expectations. A father buying a tricycle as a present for his child's second birthday or harassing or ridiculing a child for not coming first in his class are good examples of faulty limit setting. Parents should provide a role model and they should accept responsibility for their parenting behaviour. Finally, they must also accept the fact that child care problems do exist, recognize the need for outside help, seek therapeutic intervention where necessary and be prepared to change their parenting behaviour.

Based on the attitudes and child rearing practices adopted by different parents, four distinct parenting styles have been identified and it is well known that each of these parenting styles is associated with a particular developmental outcome in the child.

The following are the different parenting styles

- Authoritative

- Authoritarian

- Neglecting

- Permissive

Authoritative parents are those who adopt a warm, child centred approach coupled with a moderate degree of control that allows children to take age appropriate responsibility and allows children to develop as autonomous and confident individuals. 
These children also learn that the most effective way of settling disputes is by taking others view points into consideration within a balanced framework. This also helps in the development of good peer relationships and consequently of a good social network and they generally do well in school.

Authoritarian parents also set firm controls but they tend to be less warm and emotionally more distant from the child; they set rules without explaining why they are good rules. Their children tend to be lawabiding, shy adults who are reluctant to take initiative and not very independent. They believe that unquestioning obedience is the best way to solve interpersonal differences and problems.

Neglecting parents are those who are cold and indulge in harsh disciplinary methods such as frequent corporal punishment and have little or no supervision of their children and do little more than provide them with food and shelter. Children of neglecting parents develop adjustment problems in later life and think that aggression is an appropriate way of resolving conflicts. They tend to use aggression in managing conflicts with their peers and are at risk of developing conduct disorders and psychopathic traits.

Permissive parents are those who are warm and loving but undemanding. They also lack in disciplining skills. These children will lack competence in later life to follow through on plans and show poor impulse control.

In addition to the influence that each one of the above parenting styles has on the child, there are other factors that operate within families that hinder psychosocial development. They are:

- Parental problems

- Marital discords

- Family disorganization

Parental Problems such as alcoholic father, mental illness in the mother (such as depression) and criminality of the father will all interfere with secure attachment, and such parents may not be able to provide their children with adequate warmth and affection and exercise proper control in providing their child a safe environment.

When there is marital discord, children may witness quarrelling between parents. They may be drawn into loyalty conflicts; for e.g. they may be torn between the father and the mother. The child may feel unwanted; childbirth may have coincided with a major crisis between the parents following which the child becomes unwanted or hated with the child being expected to resolve the problem. Children may believe that they are responsible for the marital disharmony. Therefore marital discord prevents the parents taking a cooperative approach when dealing with the child because they can never discuss and take decisions together with regard to the well-being of the child.

Family disorganisation is characterized by inconsistent rules, unclear roles, absence of routines, lack of proper communication skills and lack of problem solving skills by the parents.

On looking back, you would probably recall several instances when you have come across the type of incorrect parenting roles and attitudes that I have already taken you through, among families that you have been looking after.

Some faulty parenting styles that we encounter as clinicians are:

- Inconsistent disciplining

- Faulty communication

- Not allowing the child to develop autonomy and self esteem and

- Not providing age appropriate stimulation

Inconsistent disciplining that we encounter, include over-permissiveness, over-disciplining, inappropriate reward and punishment, inadvertent reinforcement and wrong limit setting.

Some faulty communications that I have noticed are conflicting messages by parents, use of child as the medium of communication between parents, unusual expectation inappropriate to the age of the child and reversal of roles - getting the child involved in decision making at an inappropriate age or on issues where the child's voice or the opinion is uncalled for.

Not allowing the child to develop autonomy and selfesteem is another faulty parental style. Over protectiveness resulting in low self esteem (e.g. in cases of asthma or epilepsy), unusual habits not in keeping with the age (e.g. feeding a 4 yr old with a bottle), constant criticism (criticizing each and every act of the child) and comparison with siblings and other children are some of them. 
Not providing age appropriate and inadequate intellectual stimulation is equally harmful. It is now known that proper and adequate age appropriate stimulation can raise the I.Q. of a child by as much as 10 I.Q. points. Therefore lack of stimulation such as not playing with the child, not providing adequate correct educational material, not providing a secure base for him to explore the environment, not showing adequate love and empathy are some of the errors that we commonly encounter.

Although there are so many organizations and well coordinated programmes to monitor and promote parenting in countries such as the U.K and the U.S.A, this issue of parenting still receives very low priority in our child care programmes and in the political agenda. In Sri Lanka we work with a lot of constraints and it is very important that we target children in the most effective way. Although a wellcoordinated child mental health programme is necessary to address these issues, there is no such programme at present. Therefore, in the absence of an organized child mental health programme in this country, the onus of this task initially rest with the paediatricians. The proposed community health care programmes for the future with the active participation of the community paediatricians could certainly serve as a launching pad for this purpose. Therefore, we will be failing in our duty if we do not pay some attention to this important aspect of child care.

\section{How we can be of help in this regard}

As paediatricians we can improve parenting roles in a number of ways:

- As individuals in our clinical practice.

- As a group acting through the College of Paediatricians.

- As trainers.

As a clinician one may be able to offer help by acknowledging that there is a problem, showing concern about it, giving advice and referring to the relevant authorities where necessary. As an organized body, we to a great extent could work in collaboration with psychiatrists, other mental health care personnel, primary healthcare personnel, schoolteachers, NGOs', community leaders and the clergy.

The College should continue to pursue the concept of the community paediatrician and solicit support from the administrators for its successful implementation. As trainers we could suggest changes to the paediatric postgraduate curriculum to have a greater mental health input so that the future paediatricians would be equipped with the necessary knowledge to handle basic issues related to child mental health. A survey conducted recently in the U.K of paediatricians appointed to consultant posts revealed that the areas of greatest lack were in the management of child mental health problems and administration. This situation could be remedied by paying more emphasis on issues related to child mental health in our DCH and the MD programmes. Apart from training medical personnel we could also help train the first contact persons such as the family health workers and the nurses. I think it wouldn't be a bad idea even to reach out to the schoolteachers, perhaps with the help of the NIE, Maharagama just to create awareness among them.

\section{Constraints for parenting}

- Poverty is the biggest constraint in the Sri Lankan society. Lack of housing and overcrowding will not create a healthy environment conducive for proper parenting. Poor nutrition also will indirectly affect the biological maturity of the child. Inattentive care or caring for the young by older children may be encountered in situations where both parents have to go for work leaving the children unsupervised or in the care of an older child. This practice is not only unacceptable but would also affect the schooling of older children. Those who work till late may not have time to spend with their children and this can be detrimental to their development. Lack of resources to provide adequate intellectual stimulation and also not using even the available resources wisely is another factor linked with poverty. At times, the inability to cope with stress will be projected at children and finally the exodus of mothers to the Middle East with all its undesirable outcome are all linked to poverty.

- The next constraint is the lack of political will. Power is closely linked to money in our society and some believe money is everything. As a result there is total disregard for accepted social norms and this is obvious even on our roads. Children who grow up in this type of background will be inadvertently influenced by the society in which they live. Therefore, a firm political commitment is needed to put things right before it is too late. 
- Inadequacy of the support systems for the mother and for the mother to be. Poor nutrition among girls and young women of child bearing age, and particularly pregnant mothers will result in giving birth to low birth weight babies with all its' attendant complications. Under nutrition among women has a special dimension in countries such as ours with male dominant societies where even pregnant women try to appease the husbands and children first and be happy with what ever is leftover for them. Therefore, an attitudinal change in creating awareness is needed.

- Lack of trained personnel to spear head some of these mental health programmes is a problem that we are faced with at the moment. Therefore, policy makers and those who plan the health cadres for the future should take note of this situation.

- Funding. In addition to a firm personal commitment financial commitment too is necessary for the successful implementation of such programmes. Therefore, at least some budgetary allocation must be made for the promotion of child mental health in the country. NGOs' can certainly assist in this regard.
Our ultimate aim should be to see that every child born to this world is a healthy child with optimum physical and mental development, has an identity of his own, knows his capabilities, can make correct decisions, is able to cope with stress and resolves conflicts in life skilfully, has good interpersonal relationships and communication skills, is productive to the society and is an ideal future citizen.

Let me conclude my address with a well-known poem by William Wordsworth

My heart leaps up when I behold A rainbow in the sky:

So was it when my life began;

So is it now I am a man;

So be it when I shall grow old, Or let me die!

The child is father of man; And I could wish my days to be Bound each to each by natural piety. 
